\section{Patient and public involvement in translative healthcare research}

\section{Patient and public involvement}

\author{
Clive Savory
}

Technology Management Research Group,

Department of Communication and Systems, Faculty of Maths, Computing and Technology, The Open University, Milton Keynes, UK
191

Received 11 December 2009 Revised 29 January 2010 Accepted 12 February 2010

\begin{abstract}
Purpose - This paper aims to set out a framework that can be used for locating strategies for incorporating patient and public involvement (PPI) in the wider process of translative healthcare research.

Design/methodology/approach - This paper is analytical and synthesizes knowledge from several disciplines in order to provide a coherent framework for understanding the scope and purpose of PPI. The framework sets out four idealised strategies for PPI based on mode and purpose of involvement. The paper concludes by summarising a range of implications for organisations involved in the governance of translative healthcare research.

Findings - The framework defines four idealised strategies for PPI in translative healthcare research. The strategies range in purpose from collecting patient data, through to improving public involvement and knowledge with respect to healthcare research.

Practical implications - The framework presented has direct relevance for agencies concerned with the management and governance of translative healthcare research. The framework is relevant when either designing or auditing research pathways in terms of PPI activities. The framework is also important in highlighting to healthcare leaders, researchers, patients and the wider public, the potential role of participation in healthcare research.

Originality/value - This paper's value is that it combines perspectives from the wider literature on innovation, user-led design and participation, to the problem of translative healthcare research.
\end{abstract}

Keywords Patients, Innovation, Public policy, Research, Health services

Paper type Viewpoint

\section{Introduction}

Patient and public involvement (PPI) is not yet a precisely defined concept but it is becoming an important pillar of healthcare policy where it has two overarching purposes: to improve the quality of services; and to enhance accountability for public spending (House of Commons Health Committee, 2007). It is also seen as a way of allowing "patients to drive the design and delivery of high-quality services" (Department of Health, 2009a).

The political imperative for supporting improvement in service quality through PPI was heralded in the UK government's vision for a new NHS (Department of Health, 1998). From 1999 onwards the relationship between PPI and clinical governance within the NHS strengthened when the UK Government defined the role of clinical governance

The author would like to thank participants at the PPI Workshop held by the Oxford Biomedical Research Centre on 2 October 2009. Many of the ideas within this paper were developed in response to comments and issues raised within the workshop.

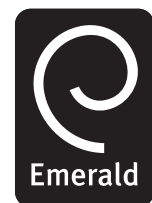

Clinical Governance: An International Journa

15 No. 3,2010 pp. 191-199

(C) Emerald Group Publishing Limited 1477-7274

DOI $10.1108 / 14777271011063823$ 
CGIJ

15,3

192

in terms of a systematic approach to quality improvement in the NHS (Department of Health, 1999). In time however, the emphasis of clinical governance has widened from its initial concern to reduce self-regulation and clinical autonomy, a direct result of high profile clinical failures (Kennedy, 2001; Redfern et al., 2001). The initial impact of these crises may have been to strengthen regulation of patient and public involvement, for example through more rigorous processes for gaining consent. The clinical governance agenda has however now widened and recognises the broader need for PPI as an integral part of the strategy for setting standards, improving quality and monitoring services. Key initiatives driven by the Department of Health attempted to integrate PPI as an intrinsic part of improvement processes. Of particular note is how PPI has been encouraged and implemented within the development of: clinical care guidelines by NICE; National Service Frameworks and the Annual Patient and User Surveys.

The NHS Act 2006 has now placed a legal expectation that NHS organisations will promote PPI (DH Commissioning and System Management, 2008, p. 130) and the NHS Constitution sets out explicit rights in relation to participation by the public in development of healthcare services:

You have the right to be involved, directly or through representatives, in the planning of healthcare services, the development and consideration of proposals for changes in the way those services are provided, and in decisions to be made affecting the operation of those services (Department of Health, 2009b, p, 7).

Guidelines for managing the PPI process in specific care pathways have also been developed in key areas including:

- urgent and emergency care;

- mental healthcare;

- end of life care;

- maternity and new born care;

- children's and young people's health services;

- planned care;

- staying healthy; and

- long term conditions (NCI, 2009).

Within the governance of healthcare research the importance of PPI is also being driven up the agenda as a way of:

- helping researchers to identify and ask the right questions in the right way;

- making sure that health and social care research is relevant to patients, people using services and the public;

- getting involved in the research process itself, whether designing, managing, undertaking or disseminating research. (INVOLVE, 2009).

In the UK, the Cooksey Report highlighted that central to the improvement of the healthcare services in the UK, is the process of translating health research into healthcare improvement, through a pathway starting with basic research and finishing with healthcare delivery (Cooksey, 2006, p. 99). The report recommended that a range of existing and new agencies needed to work together to manage the translative health 
research pathway, including: the Medical Research Council (MRC), Healthcare Technology Assessment Agency (HTA), National Institute for Clinical Excellence (NICE), Connections for Health (CfH) and the NHS itself. However, most crucially the report highlighted two fundamental problems with the pathway, described as gaps in the translation of health research into healthcare improvement. The first gap was concerned with developing the outcomes of research into a form where they can be commercialised or disseminated into healthcare practice. The second gap was concerned with ensuring that the products of research can be implemented into routine clinical practice. Both these gaps in the translative research process can be supported through better use of PPI. The result of increasing the "voice of the customer" into both of these stages will be an improvement in the extent to which the right research is implemented in the optimum manner.

PPI is now recommended as an integral feature of the pathway for translation of healthcare research into healthcare practice and the National Institute for Health Research (NIHR), in particular, now requires researchers to show how PPI will be incorporated into the research it commissions.

However, there is no clear definition of what defines PPI within translative research, either in terms of its function or who should be involved. This paper sets out how various PPI strategies can be united within a distinct framework by drawing on perspectives and practices for managing technological innovation, from sectors other than healthcare.

Within the wider field of technological innovation, there has been a growing recognition that the development of innovations, and the new knowledge that underpins them, no longer takes place solely within specialist research institutes (Lettl et al., 2008). It has also been recognised that innovation does not follow simple linear pathways, but instead takes place through complex networks often involving iterative cycles of activity (Rothwell, 1992). The role of customers and expert users of technologies has been recognised as critical to the development of innovative technologies. This shift from closed to open innovation paradigms (Chesbrough, 2003) is now reflected in the growing recognition of the role of PPI in translative healthcare research. This is timely as many healthcare innovations developed through translative research projects have potential for radical healthcare service re-design.

\section{Purpose of PPI}

In order to understand how PPI fits into translative research it necessary to be clear about the purpose of PPI. Traditionally clinical research has involved patients and the public (P\&P) as an integral part of the research process but the primary purpose of including them was almost always as a source of research data. This paper would argue that translative research requires a much wider conception of the potential contribution by P\&P. Translative research is explicitly focused on innovation of healthcare technologies and as such mirrors problems around participation in other fields of innovation outside healthcare, such as new product development (von Hippel, 2005), computer software (Flowers et al., 2008), re-design of public services (Dibben and Bartlett, 2001) or development of information systems (Stowell and West, 1994). In all of these areas, there has been recognition of the need to include customers and technology users within the development processes.

\section{Patient and public involvement}

193 
CGIJ

15,3

194
Achieving the effective inclusion of P\&P within healthcare technology innovation requires the range of participation modes and their purpose to be clearly defined. Elements of translative research can be conducted: on, with, or by P\&P. Thus, the modes of participation will reflect differences in the level of control over the research process given to P\&P. This balance will depend on the purpose of the PPI activity and the extent to which the research is done in consultation, collaboration or under the control of P\&P (Schein, 2000, p. 228).

Before considering the mode of participation, it is worth recognising the range of stakeholders that would be represented by P\&P. While the participation of patients requires little clarification, it should be noted that the inclusion of the "Public" in translative research implies involvement of many different stakeholders. Categorisation of these stakeholders may be most usefully done by considering the focus of involvement they each may have. The primary concern of patients is likely to be how the research will affect themselves and others with similar conditions. For individual carers, the focus of concern is the person they are caring for and other people caring in similar situations. In turn, organisations representing patient groups will have a wider focus. Participation by members of the general public will have the broadest focus of involvement, even though some individuals may not have any first hand experience of a specific healthcare issue. Put simply participation by P\&P can relate to a highly individual micro view, to one based on a macro view of society.

The role of the P\&P in healthcare research has been summarised as possible at several stages of the research cycle (Hanley et al., 2004); suggesting that involvement is possible in many activities including:

- identify research topics;

- prioritise research topics;

- commission research;

- design research;

- manage, undertake and analyse research;

- dissemination and evaluation.

PPI can therefore be seen as an opportunity to democratise research (Fals Borda and Rahman, 1991; Reason, 1999) and ensure that it is patient-centred. This recognises the benefits of applying participatory approaches to health research (Israel, 2005). Finally, PPI can result in an improvement in the public understanding of the results of healthcare research and its impact on healthcare services. This increase in understanding is a direct consequence of participatory research emphasising co-learning between formal researcher and the P\&P; in addition to creation of other forms of knowledge beyond just the technical (Heron and Reason, 1997; Park, 1999).

PPI therefore has a purpose of extending the role taken by P\&P beyond simply acting as a means of enabling data collection. Recent development in the way that P\&P can participate in research creates potential for exciting new forms of involvement. For example, use of Web 2.0 applications can increase participation in healthcare research, but also facilitate the creation and sharing of new knowledge and insights. The use of Web 2.0 tools has the potential to: 
... create new levels of patient participation, as well as unique and unprecedented opportunities for engaging patients in their health, health care, and health research, and for connecting patients with informal and formal caregivers, health professionals, and researchers (Eysenbach, 2008).

PPI should be recognised as having several levels of potential impact on the healthcare technology systems that translational research seeks to improve or create. This suggests four levels of impact that can be achieved through PPI. First-order impact simply reflects how PPI results in healthcare researchers improving their understanding through collecting better data from patients or the public. Second-order impact results when patients and the public have an opportunity to contribute more widely to the research process, for example, by informing its design or taking an active role in its conduct. Third-order impact results in P\&P taking control by the prioritising of translative research objectives. Finally, the fourth-order impact of PPI is the most far-reaching, enabling the P\&P to develop significantly new levels of knowledge resulting in an improved public understanding of the outcomes of translative research.

Figure 1 combines the three elements effecting how PPI strategies may relate to one another and helps define a space within which PPI strategies can be defined. This space is defined in terms of the purpose of the participation that is sought, the category of stakeholder who is to be encouraged to participate and the level of impact on the healthcare systems that is sought.

\section{Four idealised PPI strategies}

The PPI component of a translative research project will inevitably have a complex mixture of both participants and their roles. However, Figure 1 is useful in highlighting the range of potential PPI strategies, Points A, B, C and D relate to four idealised types of PPI strategy.

Strategy A represents PPI strategies that focus on the participation of patients with the primary purpose of collecting data. This relates very much to the participation required within most clinical trials. At its most basic level, this type of strategy requires little input from the patient in terms of designing or conduct of the research and is likely to have an impact limited to simply ensuring that data for the research are

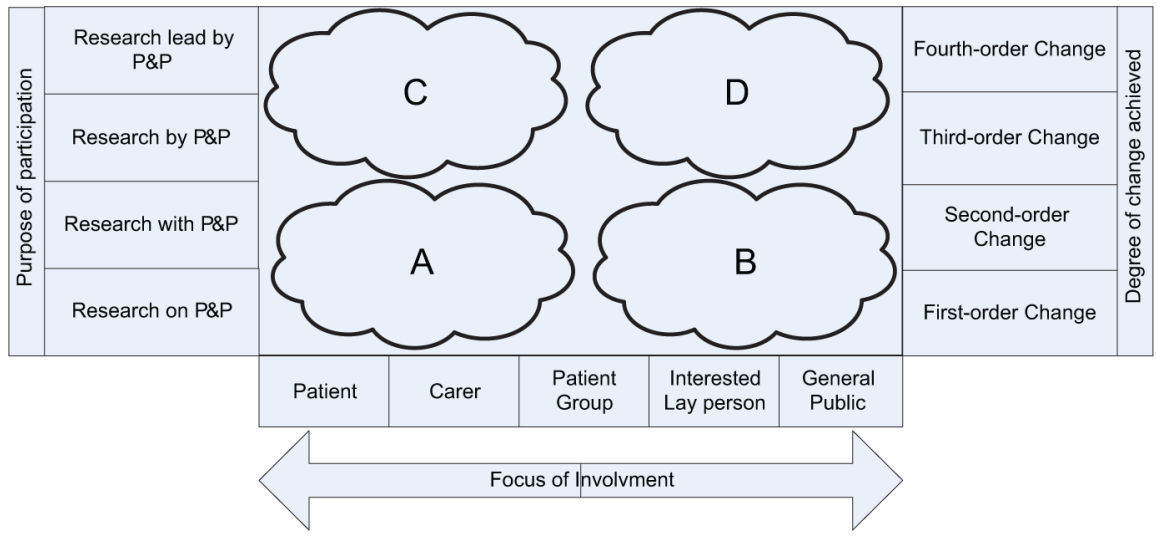

\section{Patient and public involvement}

195 
CGIJ

15,3

196 collected appropriately. This type of strategy can be characterised as concerned with "collecting patient data". Most randomised clinical trials would fall into this type of strategy. However, the strategy extends to emphasise research "with" rather than "on" patients, creating a different dynamic. A good example of this is the way that patients and carers are encouraged to be involved in diabetes research through the UK Diabetes Research Network.

Strategy B represents a broader based PPI strategy involving data collection from a wider range of stakeholders. The broader scope of this strategy, compared to A, suggests the potential for wider perspectives to be contributed to the research, beyond that of patients. This may be appropriate where the research has potential to change healthcare service designs and attitudinal data is required that relates to potential change. This type of strategy might be characterised as "Patient and Public Consultation Research". Positive examples of direct engagement of the public in identifying health priorities do exist. The style of these types of intervention may take the form of "focus groups" or "citizen panels" (Bowie et al., 1995). More sophisticated models such as "citizens juries" place emphasis on the fairness of the participation process and the extent to which participants are given opportunity to access and interpret relevant information (Abelson et al., 2003). Used wisely, this type of strategy can be used to address novel or controversial issues such as introduction of genetic testing (Gollust et al., 2005).

Strategy $\mathrm{C}$ represents a strategy where the mode of patient involvement is complex with them being involved in the design, conduct and even analysis of the research. This is perhaps best described as a "Patient-Led" strategy. When most successful, the involvement will result in valid and reliable data for translative research, in addition to improving the level of participants' knowledge. For example, through their own research, a group of patients can create new understandings of how best to manage their own conditions. This type of involvement can have wide ranging impact on the effectiveness of treatment for the individual but also impact on service design. One area of health research where participative, user-led approaches have been shown to be very effective is mental health. The "Camden Project" facilitated researchers who themselves had had experience of using mental health services to develop research questions and activities that engaged other local service-users, resulting in a better shared understanding of the issues around mental health services (Weaver and Nicholls, 2001).

Strategy D is perhaps best described as "public involvement and education". This mode of PPI is concerned with widespread public-involvement in translative research. The impact of the research is improved public understanding of science and technology underpinning healthcare services, not simply broader-based data collection. This type of strategy may be most important where high-level policy change or radical re-design of public services is required as part of the translative research pathway. This type of strategy combines the need for encouraging public participation in research that yield improved public understanding of key issues in policy and healthcare provision. It is common for technological change to result in what may be seen as counter-intuitive change to policy. For example, the implementation of primary angioplasty contributed to the debates about size and location of accident and emergency departments (Department of Health, 2008). The resulting public opposition to closure of local A\&E services may have been better understood where a PPI strategy had improved public awareness of the drivers for change. Successful examples of public involvement and education have been achieved 
in areas such as the participatory planning of maternity services in developing countries (Howard-Grabman, 1996). More recently, the use Web 2.0 tools has shown potential for underpinning this type of strategy. One example is the potential benefits of allowing patients to share and discuss their medical data over the internet (Frost and Massagli, 2008).

Strategies $C$ and $D$ in particular raise a further distinction to be made between forms of PPI. Where higher orders of change are sought through PPI, a critical dimension is the point in the research cycle in which PPI is included. Hence, strategies C\&D can be embedded in single phases of the translation pathway or integrated across the whole pathway; from the basic research stages through to healthcare delivery.

\section{Conclusion}

This paper has identified that PPI has a broader role in the translative research process than simply creating a mechanism for data collection. Instead, the paper argues that the role of $\mathrm{P} \& \mathrm{P}$ in translative research is analogous to the role of customers and technology users in other disciplines where technological innovation is a major focus. The paper highlights that within the open innovation paradigm the role of users and customers is central to the development of innovations. In turn, within translative healthcare research, there is great benefit in ensuring that the 'voice' of patients and the public is represented in all stages of the healthcare research cycle from commissioning through to dissemination and evaluation.

Clearly, the four strategies represent ideal types and it is unlikely that in practice any PPI strategy would have such a defined focus. The four strategies do however illustrate the range of ways in which PPI might be categorised. The framework in Figure 1 will therefore be potentially useful in several ways.

- Allow examples of best practice found in existing projects to be categorised.

- Identify gaps in current practice where new approaches to PPI are required. The framework makes it possible to identify what new approaches can be developed to improve existing translative research projects.

- Manage the balance between different forms of PPI activity. The balance of activities between patient and the wider public will create different benefits. This is perhaps of particular importance where the outcomes of research needs to be evaluated both in terms of service quality and accountability for use of public money; criteria that may sometimes be mutually antagonistic.

- Guide the design of PPI within specific translative research projects. The framework provides a basis for auditing a proposal for a new translative research project in terms of the PPI opportunities.

- Guide the design of PPI at different stages of the translative research pathway. The potential for use of PPI and the form that will be most effective is likely to change depending upon the point in the translative research pathway.

- Allow the balance of PPI activities within translative research to be assessed.

The recognition that PPI can be understood in terms of these ideal types has significant implications for the governance of the healthcare research translative pathway. While there are many PPI activities already taking place, there is no commonly agreed framework for considering how examples of good practice in PPI relate to the

\section{Patient and public involvement}


CGIJ 15,3

198 translative pathway. The framework in this paper provides a clear basis for analysing and organising a collection of best practice cases. The diffusion of best practices in PPI will be better supported through the use of this framework. Ideally, the framework should be used to structure a national database of PPI strategies; allowing researchers and policy makers to navigate efficiently the range of existing PPI practices and activities. As noted earlier several different agencies are involved in overseeing various stages of the translation pathway. This framework is relevant to these agencies as it has potential to inform the development of coherent PPI strategies across the whole translative pathway.

\section{References}

Abelson, J., Forest, P.-G., Eyles, J., Smith, P., Martin, E. and Gauvin, F.-P. (2003), “Deliberations about deliberative methods: issues in the design and evaluation of public participation processes”, Social Science \& Medicine, Vol. 57 No. 2, pp. 239-51.

Bowie, C., Richardson, A. and Sykes, W. (1995), "Consulting the public about health service priorities”, BMJ, Vol. 311 No. 7013, pp. 1155-8.

Chesbrough, H.W. (2003), Open Innovation: The New Imperative for Creating and Profiting from Technology, Harvard Business School Press, Boston, MA.

Cooksey, D. (2006), A Review of UK Health Research Funding, HM Treasury, London.

Department of Health (1998), “A first class service: quality in the new NHS”, Department of Health, London.

Department of Health (1999), Clinical Governance: Quality in the New NHS, original edition, HSC 1999/065, NHS Executive, London.

Department of Health (2008), Treatment of Heart Attack National Guidance: Final Report of the National Infarct Angioplasty Project (NIAP), Department of Health, London.

Department of Health (2009a), "Helping the NHS put patients at the heart of care: the patient and public engagement support programme 2009-10", Patient and Public Engagement, Department of Health, London.

Department of Health (2009b), The NHS Constitution, Department of Health, London.

DH Commissioning and System Management (2008), "Real involvement: working with people to improve health services", Department of Health, London.

Dibben, P. and Bartlett, D. (2001), "Local government and service users: empowerment through user-led innovation?”, Local Government Studies, Vol. 27 No. 3, pp. 43-58.

Eysenbach, G. (2008), "Medicine 2.0: social networking, collaboration, participation, apomediation, and openness", Journal of Medical Internet Research, Vol. 10 No. 3, p. e22.

Fals Borda, O. and Rahman, A. (1991), Action and Knowledge: Breaking the Monopoly with Participatory Action-Research, Apex Press: Intermediate Technology Publications, New York, NY/London.

Flowers, S., Mateos-Garcia, J., Sapsed, J., Nightingale, P., Grantham, A. and Voss, G. (2008), The New Inventors: How Users Are Changing the Rules of Innovation, NESTA, London.

Frost, J.H. and Massagli, M.P. (2008), "Social uses of personal health information within patientslikeme, an online patient community: what can happen when patients have access to one another's data”, Journal of Medical Internet Research, Vol. 10 No. 3, p. e15.

Gollust, S.E., Apse, K., Fuller, B.P., Miller, P.S. and Biesecker, B.B. (2005), “Community involvement in developing policies for genetic testing: assessing the interests and experiences of individuals affected by genetic conditions", Am. J. Public Health, Vol. 95 No. 1 , pp. 35-41. 
Hanley, B. et al. (2004), Involving the Public in NHS, Public Health, and Social Care Research: Briefing Notes for Researchers, INVOLVE Support Unit, Eastleigh.

Heron, J. and Reason, P. (1997), “A participatory inquiry paradigm”, Qualitative Inquiry, Vol. 3 No. 3, pp. 274-94.

House of Commons Health Committee (2007), Patient and Public Involvement in the NHS: Third Report of Session 2006-07, The Stationery Office, London.

Howard-Grabman, L. (1996), "Planning together: developing community plans to address priority material and neonatal problems in rural Bolivia", in De Koning, K. and Martin, M. (Eds), Participatory Research in Health: Issues and Experiences, Atlantic Highlands, London.

INVOLVE (2009), "Good practice in active public involvement in research", INVOLVE, National Institute for Health Research, Eastleigh.

Israel, B.A. (2005), Methods in Community-based Participatory Research for Health, 1st ed., Jossey-Bass, San Francisco, CA.

Kennedy, I. (2001), "Learning from Bristol: the report of the public enquiry into children's heart surgery at the Bristol Royal Infirmary 1984-1995”, Bristol Royal Infirmary, Bristol.

Lettl, C., Hienerth, C. and Gemuenden, H.G. (2008), "Exploring how lead users develop radical innovation: opportunity recognition and exploitation in the field of medical equipment technology", Engineering Management, IEEE Transactions, Vol. 55 No. 2, pp. 219-33.

NCI (2009), "What's going on at the Centre? PPI guides from our learning team", NCI Newsletter Issue 18, p. 2.

Park, P. (1999), "People, knowledge, and change in participatory research", Management Learning, Vol. 30 No. 2, pp. 141-57.

Reason, P. (1999), "Integrating action and reflection through co-operative inquiry", Management Learning, Vol. 30 No. 2, pp. 207-26.

Redfern, M., Keeling, J. and Powell, E. (2001), The Report of the Royal Liverpool Children's Inquiry, The Stationery Office, London.

Rothwell, R. (1992), "Developments towards the fifth generation model of innovation", Technology Analysis \& Strategic Management, Vol. 4 No. 1, p. 73.

Schein, E. (2000), "Clinical inquiry/research", in Reason, P. and Bradbury, H. (Eds), Handbook of Action Research: Participative Inquiry and Practice, Sage, London.

Stowell, F. and West, D. (1994), Client Led Design, McGraw Hill, New York, NY.

von Hippel, E. (2005), Democratizing Innovation, MIT Press, Cambridge, MA.

Weaver, Y. and Nicholls, V. (2001), "The Camden 'Alternative Choices in Mental Health' Project”, in Winter, R. and Munn-Giddings, C. (Eds), A Handbook for Action Research in Health and Social Care, Routledge, London/New York, NY.

\begin{abstract}
About the author
Clive Savory is a senior lecturer in technology management at the Open University in Milton Keynes, UK. His research is concerned with technological innovation in the UK National Health Service, in particular, how the NHS manages user-led innovation, adoption of innovative technologies and technology-enabled service re-design. Clive Savory can be contacted at: c.savory@open.ac.uk
\end{abstract}

To purchase reprints of this article please e-mail: reprints@emeraldinsight.com Or visit our web site for further details: www.emeraldinsight.com/reprints 